Article

\title{
Improvement of Air Quality and Thermal Environment in an Old City District by Constructing Wind Passages
}

\section{Chong Peng ${ }^{1, *}$, Chu Li ${ }^{1}$, Zuyu Zou ${ }^{1}$, Suwan Shen ${ }^{2, *}$ and Dongqi Sun ${ }^{3, *}$}

1 School of Architecture and Urban Planning, Huazhong University of Science and Technology, Wuhan 430074, China; E-Mails: effervesce34@gmail.com (C.L.); elaine.zou713@gmail.com (Z.Z.)

2 Department of Urban and Regional Planning, University of Hawaii at Manoa, Honolulu, HI 96822, USA

3 Institute of Geographic Sciences and Natural Resources Research, Chinese Academy of Sciences, Beijing 100101, China

* Authors to whom correspondence should be addressed; E-Mails: pengchong@hust.edu.cn (C.P.); suwans@hawaii.edu (S.S.); sundq@igsnrr.ac.cn (D.S.); Tel./Fax: +86-27-8755-7134 (C.P.).

Academic Editor: Derek Clements-Croome

Received: 9 May 2015 / Accepted: 7 September 2015 / Published: 15 September 2015

\begin{abstract}
A case study in an old city district with hot-humid climatic conditions in Wuhan, China was conducted to explore the potential renewal strategies favorable to the local residents and pedestrians. For this purpose, a comprehensive mathematical model considering the parameters such as ambient crosswind, solar radiation, natural convection, and a previously established heat transfer mechanism was employed to analyze the fluid flow and heat transfer characteristics of the study area. In addition, in the urban renewal process, five alternative renewal strategies, namely, Central Demolition (CD) Plan, Edge Demolition (ED) Plan, Wedge Shape Demolition (WSD) Plan, "L" Shape Demolition (LSD) Plan, and Cross Shape Demolition (CSD) Plan, were adopted to improve the thermal and ventilation environment of Wuhan old city district. Through simulation analysis, the temperature and velocity distributions of the original urban layout and five alternative renewal strategies were compared. It is found that the construction of an air passage within the old city district can improve the local air quality, air ventilation, and thermal environment to some extent. Among the five alternative strategies to construct air passages, CSD Plan is much better than the others. Accordingly, corresponding suggestions and strategies for urban renewal were presented.
\end{abstract}


Keywords: urban renewal; wind passage; air ventilation; thermal comfort

\section{Introduction}

Urban renewal has been one of the biggest global challenges to economic and social development in China, especially for mega and medium-sized cities during the transitional period [1-9]. Over the last few decades, along with the urban renewal process currently in place in mega cities, many subsequent serious problems concerning society [10-13], politics [14-16], economy [17-19], history [20,21], and culture $[5,22]$ have continuously emerged. Those problems have attracted worldwide attention ever since. However, poor wind and thermal environment, together with other issues such as high building density, low green coverage, and shortage of public space, has seriously lowered the living quality in the urban renewal regions [23-25]. Therefore, deliberate consideration of the environment and micro climate issues in urban planning and design deserves extensive exploration. Meanwhile, the local outdoor micro climate and the thermal comfort of human beings have also captured increasing attention [26-28], with the former mainly connected to urban planning and the latter related to indoor environments, based on which during the urban renewal process, particularly in areas with hot summers and cold winters, the local outdoor micro climate and thermal comfort of the human beings in outdoor environments should be highlighted in local development plans and building layouts.

Mirzaei and Haghighat [29] proposed a systematic approach to quantify the environmental condition inside a street canyon and evaluate the possible advantages of passive and active mitigation strategies according to a frequency of occurrence concept, and developed a computational fluid dynamic model to investigate the impact of contributing parameters on pollution exposure. Barkenbus [30] presented a study to manifest how indoor temperature settings have changed over time in the United States based on data from the Residential Energy Consumption Survey released by Energy Information Administration. The results indicate that the occupants in lower-income homes tend to set thermostats higher in winter than other income groups, but that the most intense cooling tends to take place in both low-income and high-income homes. Li et al. [31] conducted three numerical simulation experiments and a presupposition of the same total leaf area for all greening cases and studied the differences of vegetation patterns on the pedestrian thermal comfort with an evaluation index as Standard Effective Temperature (SET). Comparing the simulation results, the authors have found that the average SET in the pedestrian space has a slight difference and should be carefully compared for better outdoor pedestrian comfort. Ali-Toudert and Mayer [32] discussed the contribution of street design, i.e., aspect ratio (or height-to-width ratio, $\mathrm{H} / \mathrm{W}$ ) and solar orientation, towards the development of a comfortable microclimate at street level for pedestrians with the three-dimensional numerical model ENVI-met which simulates the microclimatic changes within urban environments at a high spatial and temporal resolution. The results indicate that the time of day and the length of the period during which extreme heat stress occurs strongly depend on aspect ratio and street orientation.

There are quite a few research publications on quantitatively modeling thermal comfort, including fluid flow and heat transfer characteristics, by various influencing factors [27,28,33-40], which indicates that the computational fluid dynamics (CFD) method is an effective way to predict the outdoor wind and 
thermal environment of the pedestrians and residents. Besides the aforementioned crucial issues, CFD method becomes effective with attention paid to the wind and thermal environment of old city districts during the urban renewal process as the residents and pedestrians seriously suffer from the abominable wind, and thermal and sanitary conditions. However, few researches have covered the wind and thermal environment during the process of urban renewal. Peng et al. [41] advanced a comprehensive mathematical model to describe the fluid flow, heat transfer, and thermal comfort of the local old city district area in Wuhan, China and presented a useful exploration on the thermal behavior of an urban renewal district under a strong ambient crosswind scenario with the CFD method. They have found that the wind and thermal environment of the old city district in Wuhan, China is obviously unhealthy for residents and pedestrians. Later, Peng et al. [42] proposed some new renewal strategies by demolishing a few old buildings to alleviate the environment of the local hot points. In addition, they also advocate that wind passages or wind tunnel network are significant in improving the urban thermal and ventilation environment.

Generally, there are two common methods dealing with old downtown areas in Chinese cities: either large-scale demolition and reconstruction or small-scale renewal. The former may damage certain historical elements, change the demographic structure in the area, and cost much more than the latter. Moreover, large-scale demolition and reconstruction takes much time. On the other hand, the latter (small-scale renewal) is much more flexible, economic and effective in improving the environment of the old city.

Recently, the issue of city pollutant dispersion has aroused worldwide attention [43-46]. The pollutant dispersion caused by exhaust emissions in urban street canyons has been experimentally and numerically analyzed [47-50]. Similarly, the adverse effect of excessive high temperature environments, as well as that of the pollutants from exhaust emissions, on human beings inside the city with high-density old buildings, narrow streets and disorderly, irregular arrangements should be seriously considered. Thereby, an elaborate design of urban street canyons in old city districts will not only be helpful for the city pollutant dispersion, but also be very helpful for improving ventilation and heat transfer.

In the previous research work [42], the authors mentioned in the concluding remarks that creating wind channels in the prevailing wind direction is useful for the improvement of the thermal and ventilation environment of the old city districts. However, this predication has not been verified yet. This paper, thus taking the Dazhimen neighborhood in Wuhan city as an example, has analyzed the impacts of different renewal strategies on the wind and thermal environments in the local renewal community at the small scale through the construction of a few wind passages to improve the wind and thermal environment in the old city district. Besides, the paper has established a numerical model to simulate the wind and thermal conditions, with air circulation, heat transfer, natural ventilation, and other factors taken into account,. Finally, the paper has put forward an optimized renewal plan for the old district after simulating and comparing several alternative renewal proposals. 


\section{Study Area and Mathematical Model}

\subsection{Study Area}

In order to analyze and compare the effectiveness of different urban renewal strategies, the paper has conducted a case study in a special old city district, which is currently the key during the process of urban renewal. The study area is one of the typical old city districts on the west bank of Yangtze River as presented in previous studies [41,42]. The reasons for taking this region as the case in this study are: (1) the previous study and the previous verified mathematical models can be used without further validation; and (2) the urban morphology in this area is comparably unfavorable and the analysis can serve as guidance for the Chinese urban renewal since this urban morphology is very common in China. Within the study region, old buildings were scattered around facing various directions with very limited open space in-between, which impedes natural air flows and therefore exacerbates the poor outdoor thermal and wind conditions.

\subsection{Mathematical Model}

The thermal behavior of the outdoor environment in an old city district is affected by several factors: ambient crosswind velocity (ACV), solar radiation, solar time, season, air temperature and humidity, land form, city afforestation, distributions of the lakes, rivers, land, and building distribution. Especially, season has a significant effect on the solar radiation intensity, solar time, and air temperature, ACV significantly influences the heat transfer process among the ground surface, buildings, and ambiance whereas city afforestation significantly decreases the air temperature with lakes and rivers increasing the air humidity. All these parameters have strong correlation in the complex system.

Firstly, the natural convection effect due to the temperature difference between the ground surface and the air under gravity should be considered. The existence of ACV confirms that the fluid flow is a mixed convection, but the forced convection overwhelms the natural convection when ACV is more than a few meters per second. Therefore, the turbulent model is selected to describe fluid flow within the system. Also, the density difference in the whole computational model is so small that it can be neglected in the inertia terms in Mass and Energy equations, but the term of density difference multiplied by gravity is sufficiently strong to make the specific weight appreciable in the Momentum equation. Thereby, Boussinesq approximation is used in the numerical analysis. Accordingly, Mass equation, Navier-Stokes equation, Energy equation, and Realizable $k$ - $\varepsilon$ equations are adopted:

$$
\begin{gathered}
\frac{\partial \rho}{\partial t}+\frac{\partial\left(\rho u_{i}\right)}{\partial x_{i}}=0 \\
\frac{\partial\left(\rho u_{i}\right)}{\partial t}+\frac{\partial\left(\rho u_{i} u_{j}\right)}{\partial x_{j}}=\rho g_{i}-\frac{\partial p}{\partial x_{i}}+\frac{\partial \tau_{i j}}{\partial x_{j}} \\
\frac{\partial\left(\rho c_{p} T\right)}{\partial t}+\frac{\partial\left(\rho c_{p} u_{j} T\right)}{\partial x_{j}}=\frac{\partial}{\partial x_{j}}\left(\lambda \frac{\partial T}{\partial x_{j}}\right)+\tau_{i j} \frac{\partial u_{i}}{\partial x_{j}}+\beta T\left(\frac{\partial p}{\partial t}+u_{j} \frac{\partial p}{\partial x_{j}}\right) \\
\frac{\partial}{\partial t}(\rho k)+\frac{\partial}{\partial x_{i}}\left(\rho k u_{i}\right)=\frac{\partial}{\partial x_{j}}\left[\left(\mu+\frac{\mu_{t}}{\sigma_{k}}\right) \frac{\partial k}{\partial x_{j}}\right]+G_{k}+G_{b}-\rho \varepsilon
\end{gathered}
$$




$$
\frac{\partial}{\partial t}(\rho \varepsilon)+\frac{\partial}{\partial x_{j}}\left(\rho \varepsilon u_{j}\right)=\frac{\partial}{\partial x_{i}}\left[\left(\mu+\frac{\mu_{t}}{\sigma_{\varepsilon}}\right) \frac{\partial \varepsilon}{\partial x_{j}}\right]+\rho C_{1} S \varepsilon-\rho C_{2} \frac{\varepsilon^{2}}{k+\sqrt{v \varepsilon}}+C_{1 \varepsilon} \frac{\varepsilon}{k} C_{3 \varepsilon} G_{b}+S_{\varepsilon}
$$

In the equations above, variables such as velocities and temperatures are all time-averaged values, and the stress tensor $\tau_{i j}$ is given as follows:

$$
\tau_{i j}=\eta \frac{\partial u_{i}}{\partial x_{j}}-\rho \overline{u_{i}^{\prime} u_{j}^{\prime}}
$$

$\mathrm{G}_{k}$ denotes the generation of turbulence kinetic energy because of the mean velocity gradient, and $G_{b}$ the generation of turbulence kinetic energy due to buoyancy. $\mu_{i}$ is eddy viscosity:

$$
\begin{gathered}
G_{k}=\rho \overline{u_{i}^{\prime} u_{j}^{\prime}} \frac{\partial u_{j}}{\partial x_{i}} \\
G_{b}=-\beta g_{i} \overline{u_{i}^{\prime} T^{\prime}} \\
\mu_{t}=\rho C \frac{k^{2}}{\varepsilon}
\end{gathered}
$$

In Equation (5), the constant $C_{1}$ can be defined as follows:

$$
\begin{gathered}
C_{1}=\max \left[0.43, \frac{\eta}{\eta+5}\right] \\
\eta=S \frac{k}{\varepsilon} \\
S=\sqrt{2 S_{i j} S_{i j}}, S_{i j}=\frac{1}{2}\left(\frac{\partial u_{j}}{\partial x_{i}}+\frac{\partial u_{i}}{\partial x_{j}}\right)
\end{gathered}
$$

where $\sigma_{T}, \sigma_{k}$, and $\sigma_{\varepsilon}$ denote the turbulent Prandtl numbers for $T, k$, and $\varepsilon$, respectively $\left(\sigma_{\mathrm{T}}=0.9\right.$, $\left.\sigma_{k}=1.0, \sigma_{\varepsilon}=1.3\right)$, and $\mathrm{c}_{2}$ is a constant for turbulent model $\left(\mathrm{c}_{2}=1.92\right)$. However, $\mathrm{c}_{\mu}$ is no longer a constant as it is in the standard $k-\varepsilon$ model [51].

In addition, the above analysis also takes air humidity, solar radiation, shadow effect, and view factors among different surfaces into consideration [41,42].

\subsection{Boundary Conditions}

When considering the micro climate and pedestrian thermal comfort influenced by ACV, water vapor, and solar radiation in the old city district, we should carefully investigate the boundary conditions for the system. Detailed descriptions of the boundary conditions are shown in Figure 1 and only Northeast $\mathrm{ACW}$ has been considered as the prevailing wind.

\subsubsection{Inlet Boundary}

The prevailing ambient crosswind velocity (ACV) under consideration in this article shown in Figure 1 is Northeast wind in summer. ACV varies significantly with a whole day's time slots, which causes remarkable changes of air temperature and relative humidity ratio. Therefore, ACV is a crucial factor determining thermal comfort in this study. Consequently, the case study is based on the assumption that 
$\mathrm{ACV}$ is fully flexible and the air temperature is a constant before the wind flows into the internal space of this model.

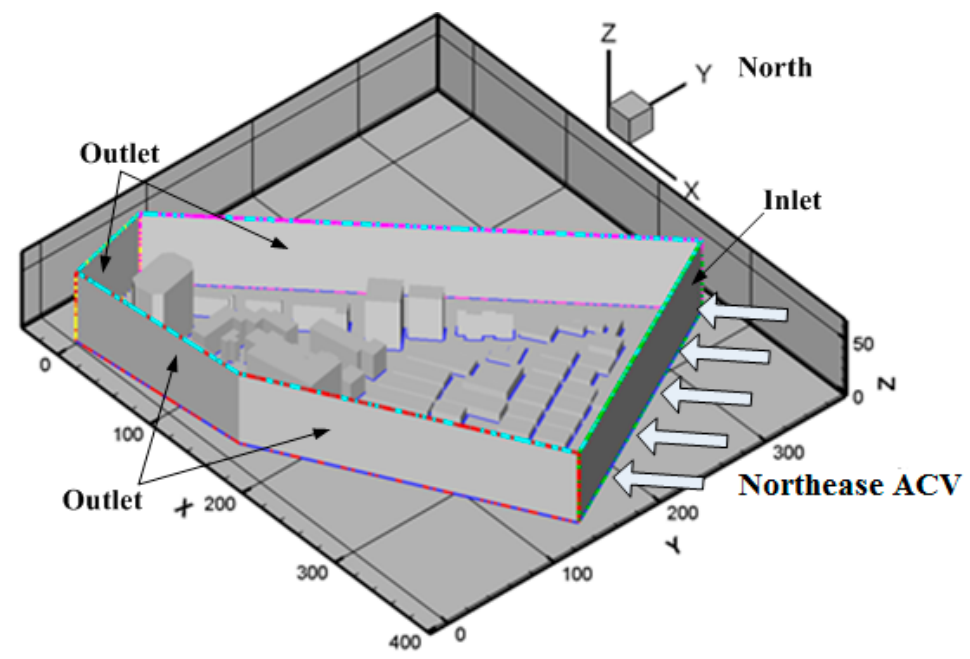

Figure 1. Boundary conditions of the study area.

According to the logarithmic law of wind speed profile in an atmospheric boundary layer proposed by Prandtl in 1932, ACV inlet velocity can be calculated by the following Equations (13) and (14) [52]:

$$
\begin{gathered}
v=w=0 \\
u=1 / \kappa \cdot\left(\tau_{s} / \rho\right)^{1 / 2} \cdot \ln \left(z / z_{0}\right)
\end{gathered}
$$

where $\tau_{s}$ stands for ground surface shear stress and $z_{0}$ for ground aerodynamic roughness length. The specific value of $z_{0}$ for different terrain is available in charts such as one value used by Cermak [53]. In this case study, $\kappa$ and $z_{0}$ are set as 0.4 and $0.01 \mathrm{~m}$, respectively. Then, $\tau_{s}$ can be calculated from a given value of wind speed $u$ at a known height, which is the top surface of the highest building across the study area in this case.

\subsubsection{Outlet Boundary}

In many cases, the geometrical models were generally regarded as cubes [54-57] and numerical simulations were performed in which the results agreed well with the experimental results. In the CFD simulation thereof, the lateral and top surfaces were regarded as inviscid wall conditions since the surface did not have significant influence on the calculated results around the target building. It is known that employing the inviscid wall condition in the large-sized computational domain will make the computation more stable [54]. However, since the geometrical model is not a cube and the lateral surfaces of the model are not distant away from the target building where those surfaces are surrounded by other buildings outside, it is better to set the lateral surfaces as the outlet boundary. In addition, although the top surface is several times higher than the highest target building, the top surface of the model should be regarded as the outlet boundary for wind exit due to the natural convection occurring from the temperature differences between the ground and building surface and the air in the ambience. Pressure outlet boundary condition is applied to each of these surfaces and the simplification reversing flow is normal to the boundary surface. 


\subsubsection{Wall Boundary}

Both the ground surface and all the building surfaces receive solar radiation and the temperature thereof increases. The radiation heat transfer occurs between any two surfaces. In addition, these surfaces transfer heat with air by convection and with the ambience caused by radiation. The solar radiation imposed on the ground and all the building surfaces varies with time, shape angle, view factor, and solar radiation intensity.

After considering the thermal boundary condition of the walls, the paper tries to describe the flow characteristics. According to the nonslip boundary condition of solid surfaces due to the viscosity of fluid flow, functions for the boundary layer are employed here in order to simulate the near-surface flow:

$$
\begin{gathered}
u=v=w=0 \\
\tau_{s}=\rho\left[\kappa / \ln \left(z / z_{0}\right)\right]^{2}\left(u^{2}+v^{2}\right) \\
k=\tau_{s} /\left(\rho C_{\mu}^{1 / 2}\right) \\
\varepsilon=\left(\tau_{s} / \rho\right)^{3 / 2} / \kappa y
\end{gathered}
$$

In the equations shown above, the subscript "s" means "surface value" and the other parameters are evaluated at nodes near the ground surface. In Equations (17) and (18), both the $k$ and $\varepsilon$ values are a constant across the study area which are different from the strong turbulent areas shown in Equations (4) and (5).

In this simulation, the effect of solar radiation is assumed as a heat flux being imposed upon a very thin thickness on the ground surface. The main focus of this work is to investigate the effect of wind tunnel creating strategies on the air quality and thermal comfort of pedestrian and residence. Some simplifications in treating the walls facilitates the development of the following assumptions: (a) the vibration of ACV effect is neglected and thus the time term is considered to be steady; (b) the ground layer is homogeneous and isotropic; and (c) local heat equilibrium has been achieved between the ground and the air bypassing it. All these assumptions are aimed to avoid the simultaneous analysis of more than one factor without too much deviation from real conditions.

\subsection{Validation Procedure}

There are two most commonly used methods to validate the reliability of the numerical simulation results, and the first one is to compare the numerical simulation results with the experimental data under the same working conditions [58]. In similar research work, the research group led by Blocken presented excellent comparisons [59-64]. However, if the experimental data is not easily obtainable due to difficulty in experiments or incomplete experiments, a commonly used method is to perform sub-configuration validation whose actual configuration consists of a number of generic sub-configurations, each of which contains one or several salient flow features in the actual configuration $[58,65,66]$. Here, the authors of this article used the similar mathematical models and boundary conditions as shown in $[59-61,65,66]$ where the CFD method verified in previous work has been also verified to be acceptable for the numerical analysis of the present research work. [41,42]. Thereby, the last step is to compare the 
results under different grid systems. That is to say, the grid-independent technology can be employed to verify the reliability of the numerical simulation results. In this paper, as the experiments are not completed and the corresponding results are not sufficient to compare the CFD results, the second method is used to verify the numerical simulation results.

As the geometrical model is almost the same as the previous research work [41,42], the meshing skill, computational procedure, and verification are also the same. Therefore, the hexahedral (HEX) grids are applied in the model and the mesh generation procedure of the whole geometric model is executed with the commercial software package Gambit 2.3.16. Denser grids are applied near the walls where there are anticipated relatively steep gradients in velocity, pressure, and temperature. The computations are performed through the general purpose CFD program Fluent 6.3.26, and all the influenced parameters, i.e., relative humidity, solar radiation, shadow angle, $\mathrm{ACV}$, are treated through user-defined-function (UDF) method. Besides, QUICK scheme is used to discretize the convective terms and a second order accurate treatment is used for the diffusion terms. The discretized algebraic equations are solved in a coupled manner. The iterations continue until the relative error is reduced below a threshold (i.e., $1 \times 10^{-5}$ in the mass conservation equation and $1 \times 10^{-8}$ in the energy equation).

The grid-independent method is used to obtain more accurate simulation results [41,42]. Three test cases with 3,215,478, 5,724,932, and 7,383,947 grids, respectively, are designed for the whole model under the same conditions $\left(0 \mathrm{~m} / \mathrm{s}\right.$ for $\mathrm{ACV}$ and $800 \mathrm{~W} / \mathrm{m}^{2}$ for solar radiation), and Figure 2 shows the selected grid-independent system with 5,724,932 grids of the study area. The simulations are implemented through parallel computation using four PCs with 4-core 4.1 GHz and 16 GB RAM. The numerical simulation results indicate that the temperatures in the three grid systems for a given point in the ambience are $303.45 \mathrm{~K}, 305.76 \mathrm{~K}, 306.05 \mathrm{~K}$, and the corresponding velocities of this point $0.351 \mathrm{~m} / \mathrm{s}$, $0.374 \mathrm{~m} / \mathrm{s}$, and $0.383 \mathrm{~m} / \mathrm{s}$, respectively. Hence, it can be seen that the calculation results with $5,724,932$ grids has a negligible difference with the results with 7,383,947 grids. Thereby, the results with 5,724,932 grid system can be regarded as grid-independent results, and the grid system of 5,724,932 and its grid spacing are selected as the basic mesh system for the geometrical model in this paper.

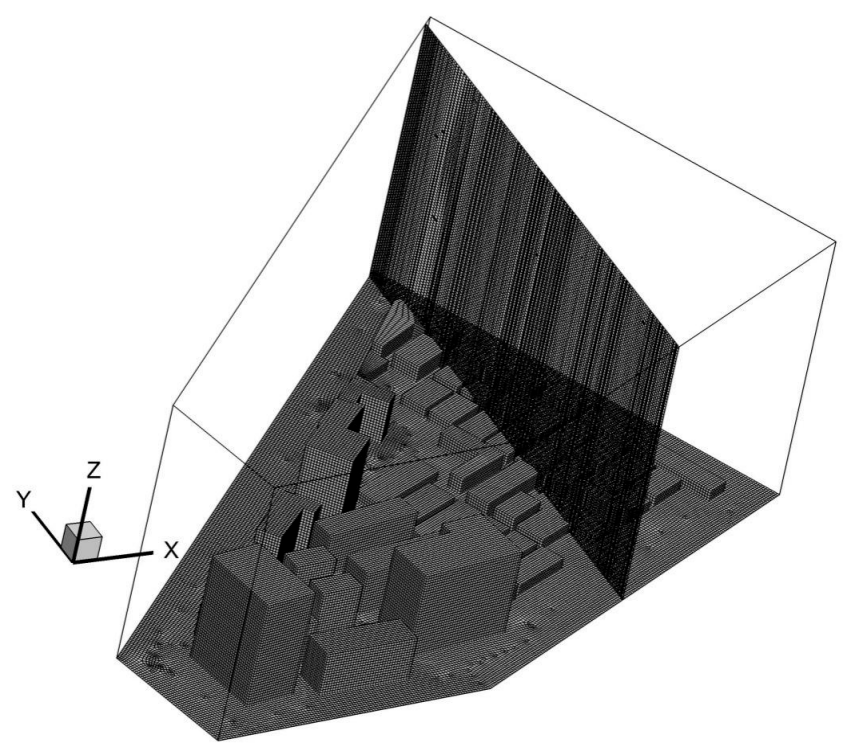

Figure 2. Grid system of the study area. 


\section{Results and Analysis}

\subsection{Results of Existing Renewal Strategy}

Actually, there are three issues concerning the health of the local residents and pedestrians in an old city district: air ventilation, thermal environment, and pollutant concentration in the air due to exhaust emissions. However, if the area has poor air ventilation, the thermal environment will deteriorate and the exhaust emissions by the cars will not easily diffuse to the outside ambience. As a result, the thermal environment and air quality in this district will become poorer, which will be harmful to the health of local residents and pedestrians.

Key parameters influencing the air ventilation and human thermal comfort include relative humidity of the moist air, ACV, solar radiation, solar time, ambient temperature, materials of the street pavement, buildings' density and height etc. Specifically, the anthropogenic thermal comfort is mainly reflected in the heat transfer conditions between human beings and the outside environment. A normal heat transfer rate can bring pleasant thermal conditions. However, if the heat transfer rate is too high, residents and pedestrians will feel uncomfortably cold and vice versa. Therefore, ambient air flow is an important factor effecting human thermal comfort and pollutant dispersion in the street canyon.

This paper mainly focuses on the effectiveness of demolition strategy utilization during urban renewal to create favorable wind, air quality, and thermal environment, regardless of the influence of different solar radiation intensity, and ACV magnitude and direction on the wind and thermal environment which have been extensively analyzed in the previous work [41]. Here, the solar radiation intensity is set as $600 \mathrm{~W} / \mathrm{m}^{2}$ at noon time in May and ACV is $10 \mathrm{~m} / \mathrm{s}$ in Northeast with the air temperature and the relative humidity $293 \mathrm{~K}$ and $75 \%$ respectively. The buildings are made of bricks with sand and cement being pasted on the surface. The ground surfaces are bricks and cement floors without plants and grass covering, which makes this area vulnerable to bad weathers.

The ambient air flow characteristics and the temperature distribution of the study area are shown in Figure $3 \mathrm{a}-\mathrm{c}$, wherein Figure $3 \mathrm{a}$ shows the overall temperature distribution on the building surface and ground level whereas Figure 3b,c depict the wind velocity and vector distributions at the horizontal section $0.5 \mathrm{~m}$ above the ground level, respectively. Due to the existence of the four buildings in the first row with only three narrow channels serving as an entrance near the inlet, the ambient crosswind air flow is blocked off. Therefore, air ventilation within the district is of unfavorable condition. Insufficient air ventilation and stagnant air cause serious thermal comfort problems during the hot-humid summer period.

Figure 4 presents a renewal strategy for the old city district: the leeward buildings in the southwest corner of the old city district are first renewed and rebuilt, and then the renewal procedure goes forward to the windward buildings in the northeast step by step. As shown in this figure, the renewed buildings will become much higher and the streets become much wider. It is expected that this renewal strategy will improve the wind and thermal environment of the whole study area. However, seen from Figure 3, air ventilation has not been significantly improved and the temperature remains high despite widened streets. This is caused by the high density of old buildings in the windward, blocking the prevailing wind from permeating the renewed area. It is obvious that the poor air ventilation correlates with high temperature. Areas with stagnant air have obviously weak heat transfer from the building and the ground 
surfaces to the air, thus causing high temperature and thermal problems. What is worse, stagnant air also restricts the dispersion of urban pollutants from various local emission sources; poisonous gases and harmful particles exacerbate the local air quality, thermal environment, and health conditions. Therefore, the existing renewal strategy shown in Figure 4 is not a successful method to improve the wind and thermal environment of the study's old city district. Here, the paper has proposed a new renewal strategy. That is leeward renewal plus constructing wind passages in windward buildings.

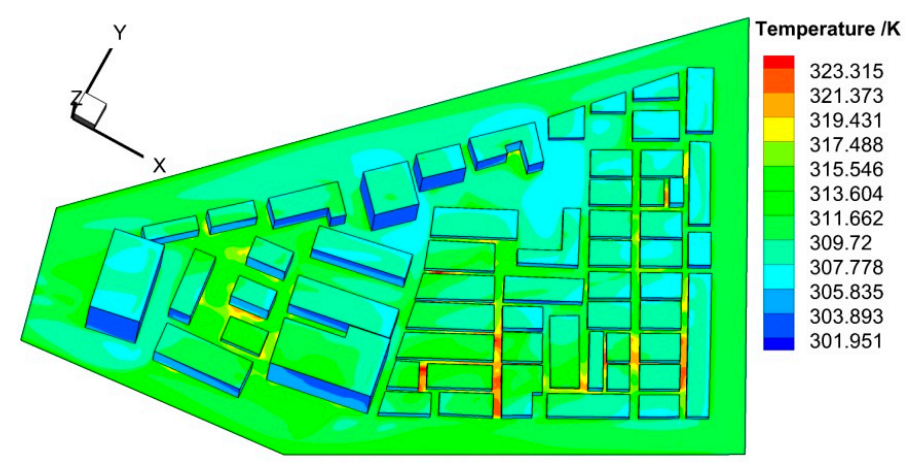

(a)

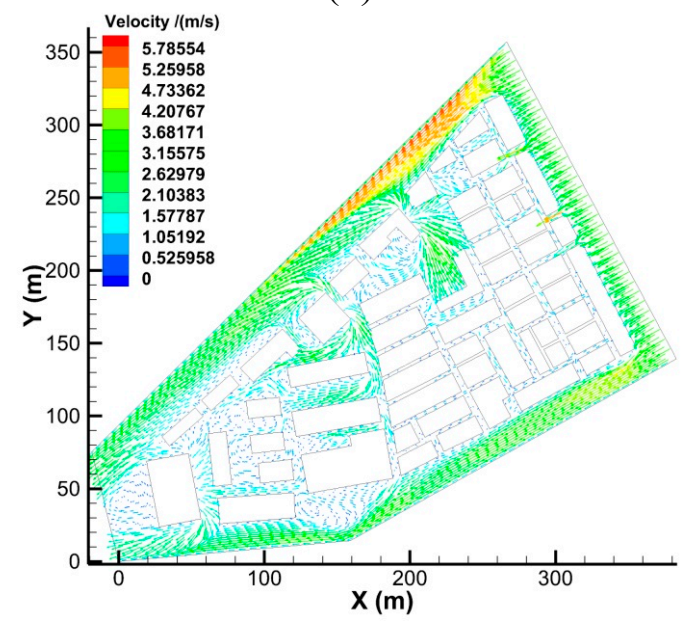

(b)

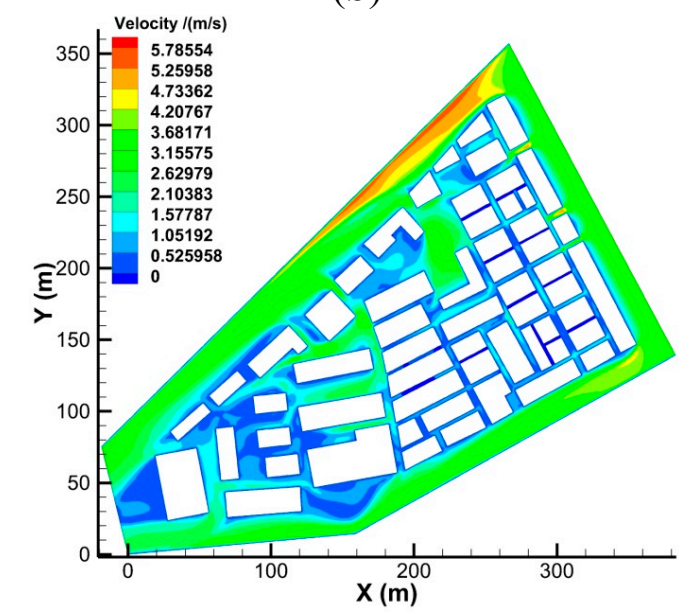

(c)

Figure 3. Simulation results for the study area: (a) temperature contour on the surface of the ground and buildings; (b) velocity contour on plane $\mathrm{z}=0.5 \mathrm{~m}$; (c) temperature contour on plane $\mathrm{z}=0.5 \mathrm{~m}$. 


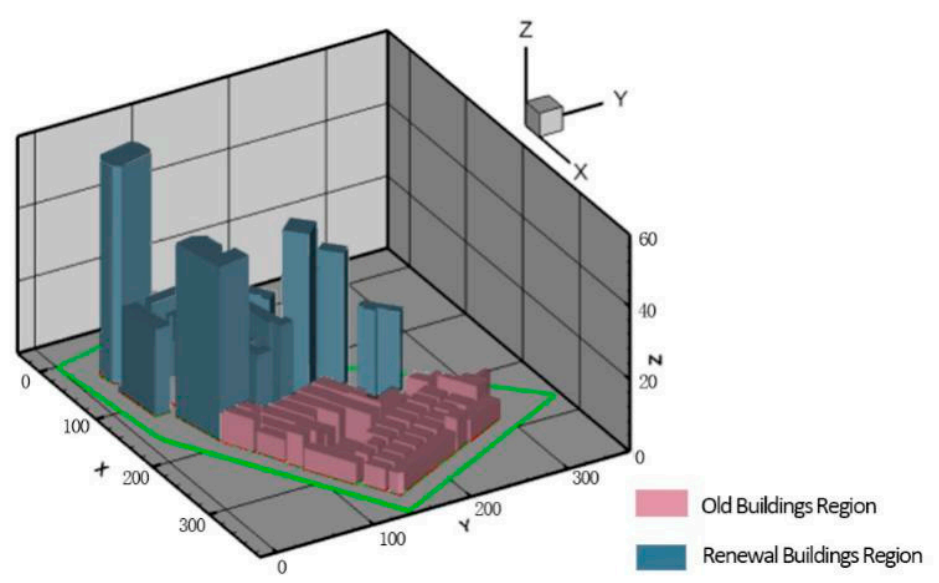

Figure 4. Computational model of the original layout under urban renewal.

\subsection{New Proposals of Renewal Strategy}

In the process of urban renewal, small-scale updates have more advantages than large-scale transformation in the actual situation. Considering the economics, historical continuity, ecology and environmental protection, the best way to adjust the local building layout plan to improve the thermal environment of the old town style without sacrificing the large scale living area is worthy of further study.

To this end, the paper puts forward the following four demolition plans to combine the existing leeward renewal strategy: (1) Central Demolition (CD) Plan; (2) Edge Demolition (ED) Plan; (3) Wedge Shape Demolition (WSD) Plan; and (4) "L" Shape Demolition (LSD) Plan. A basic rule is that the demolition area of the buildings for each demolition strategy should be the same.

According to the analysis of the study and the initial ideas that could improve the local air flow and thermal environment, the paper proposes four focused renewal programs. As shown in Figure 5a, Program (1) is Central Demolition (CD) Plan: demolishing several buildings in the middle and creating an open space. It can been seen that this new piece of open space can improve the local air thermal environment to some extent, but it cannot bring ambient crosswind into the study area as its function is not to utilize the ambient crosswind but to create open space in inner districts. Therefore, there are still large areas with high temperatures in the region.

The Edge Demolition Plan shown in Figure $5 \mathrm{~b}$ is to remove the buildings of an edge in the lower right corner of the study area. The result shows that this method can change the local environment to a certain extent to make it the same as the CD Plan, and the environmental changes needed for the entire study area are not clear. The Wedge Shape Demolition (WSD) Plan shown in Figure $5 \mathrm{c}$ is to remove the buildings in the northeast part and form a wedge-shaped open area that is located in the direction of summer prevailing winds. Undoubtedly, this shape can effectively bring the windward fresh air into the cell interior. As a result, the air ventilation, air quality, and thermal environment will all be greatly improved. However, because of the limited area of the demolished buildings, the newly built wedge-shape open entrance and the inside hollow zone is separated by an "L" shaped building, which is unable to form a good wind passage inside the study area, so the WSD Plan can be improved. 


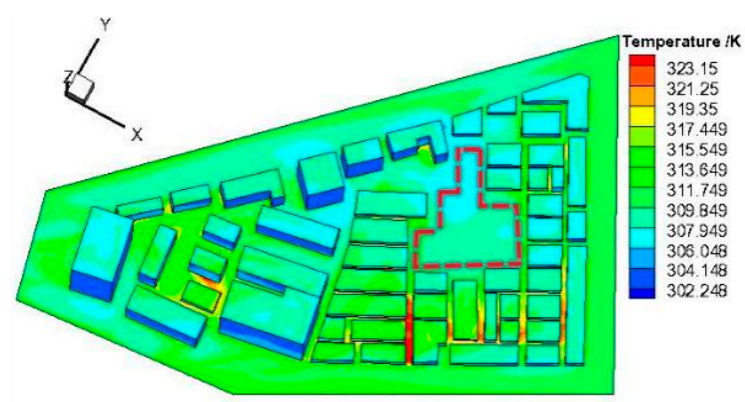

(a)

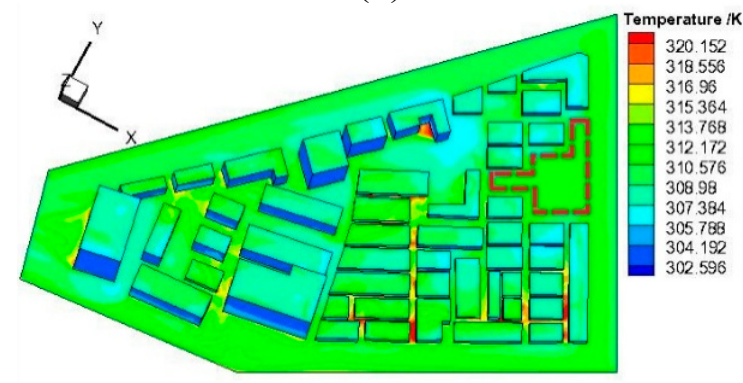

(c)

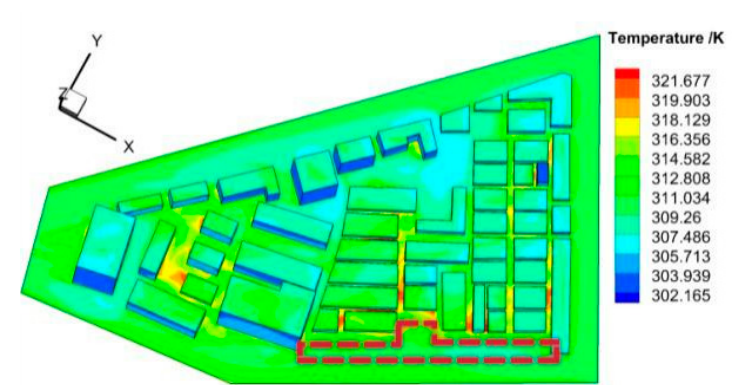

(b)

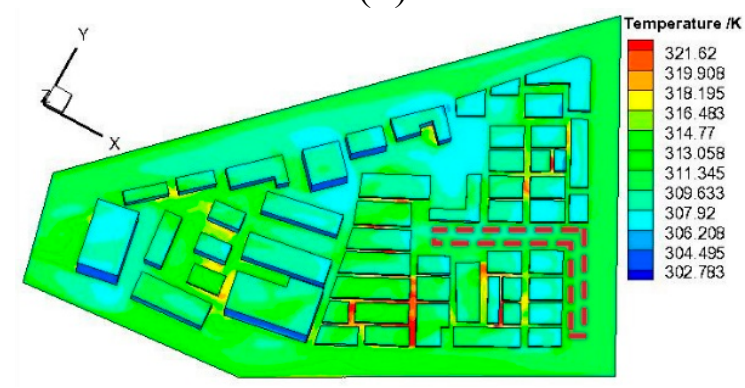

(d)

Figure 5. Comparison of temperature distributions of urban renewal plans: (a) CD Plan; (b) ED Plan; (c) WSD Plan; (d) LSD Plan.

The "L" Shape Demolition (LSD) Plan shown in Figure 5d is to remove the blocking buildings to create a wind passage in the center of the old town, trying to bring the summer prevailing winds into the interior district, which relieves the high temperature situation. Further, the bottom right building in the first row near the inlet is demolished, which is helpful to improve the wind and thermal environment of the buildings in the bottom right corner of the study area. However, this does not allow forming a smooth wind passage, and the high temperature zone still exists due to the high density of the original buildings.

Figure 6 shows a comparison of velocity distributions of the four urban renewal strategies. The height of the cross-section is $0.5 \mathrm{~m}$ above the ground. In comparison with the original mathematical model, we find that the thermal environment is significantly improved in demolished areas.

However, it can be seen that CD Plan does not have a significant influence on the surrounding buildings; both WSD Plan and LSD Plan bring the ambient crosswind into the concerned district which benefits the overall thermal environment. Between these two plans, the WSD Plan is a little bit more effective in that the upstream ambient crosswind is led into the target old city district by the wedge-shaped breach, which enhances the ventilation greatly. By comparison, the wedge-shaped entrance of WSD Plan is better than that of LSD Plan from the perspective of introducing wind.

It should be pointed out that although the ED Plan, WSD Plan, and LSD Plan can all improve the wind and thermal environment of the demolished area and enhance air flow circulation, the overall thermal environment is not improved too much due to the original high density of buildings and limited demolished areas which hinder the formation of a complete and effective wind passage. In these plans, there still exist some areas with high temperature levels which are unfavorable to residents and pedestrians. 


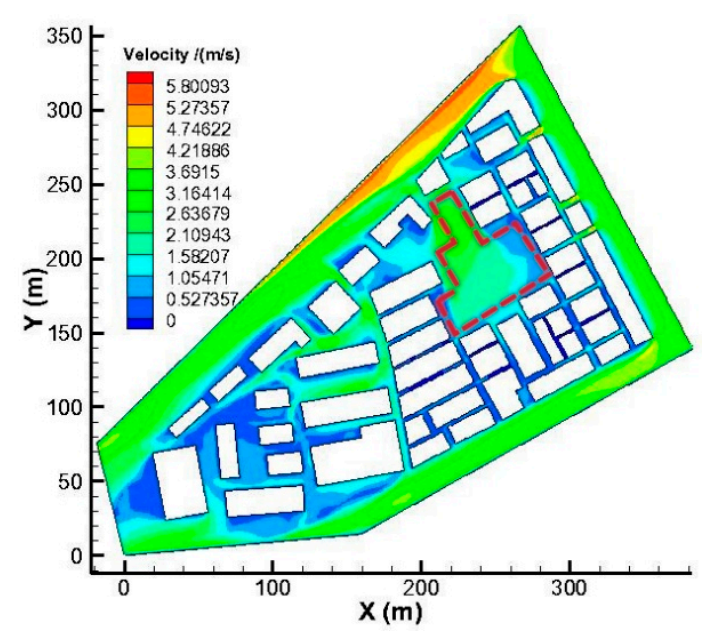

(a)

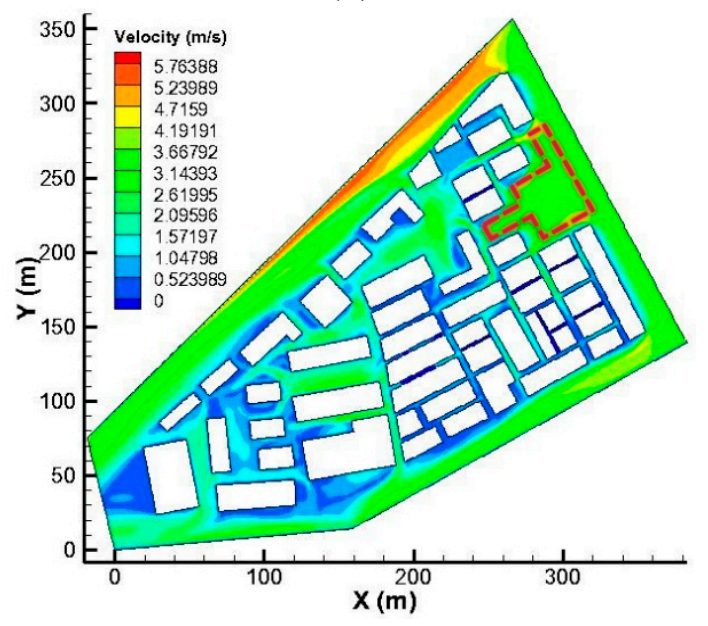

(c)

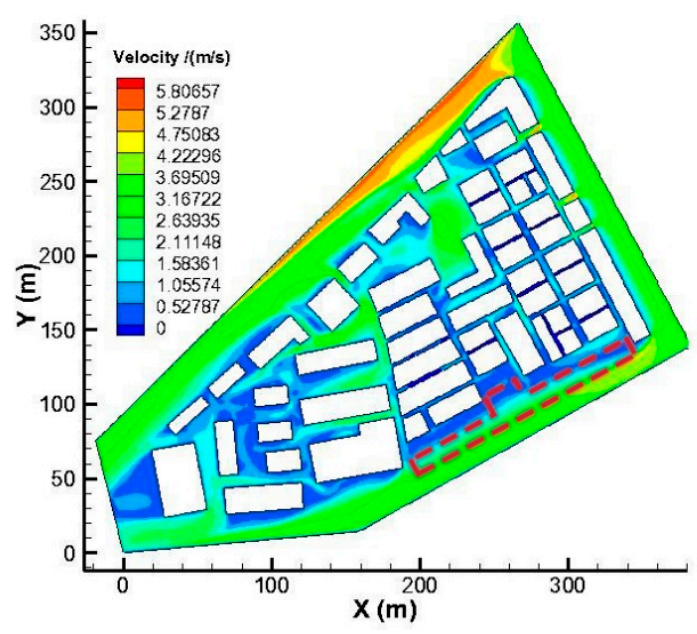

(b)

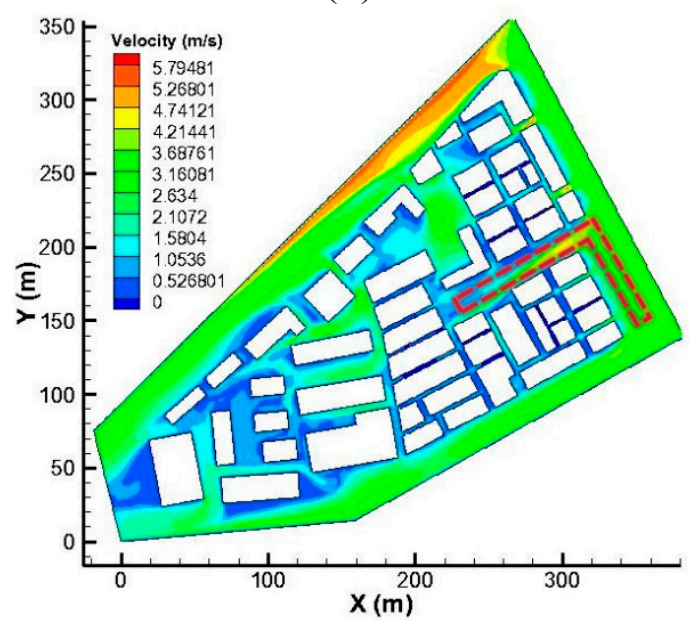

(d)

Figure 6. The comparison of velocity distributions of cross-section with height being 0.5 m of the urban renewal plans: (a) CD Plan; (b) ED Plan; (c) WSD Plan; (d) LSD Plan.

Figure 7 shows the velocity vectors of the low-rise buildings in the original old city district under different renewal strategies. It is clear that the CD Plan (Figure 7a) and ED Plan (Figure 7b) fail to construct a wind passage system for the entire old city district. As for the WSD Plan and LSD Plan, they both take into account the organization structure of the air passages flowing into the system. For the WSD Plan, the newly built wedge-shape passage and the inside hollow zone is separated by an "L" shape building. If the "L" shape building can be demolished to connect the wedge-shape passage with the inside hollow zone, a smooth flow channel could be successfully built. The LSD Plan shown in Figure $7 \mathrm{~d}$ also brings the air flow into the study area. Further, the lower left corner of the bar building is demolished, which is very helpful to connect the external environment and inner study area and thus ultimately improve the wind and thermal environment of the study area.

By comparing the results of these plans shown above, creating a smooth passage for the ambient crosswind to enter the study area is an effective way to improve the air quality, wind and thermal environment of the old city district. Due to the high density of the old buildings, the proposal to construct a wedge-shape channel to connect the inner hollow space becomes crucial. For other cases, 
if the target old city district is much larger, more complex, and has high density buildings, it is appropriate to seriously consider the strategy of creating multiple wind passages.

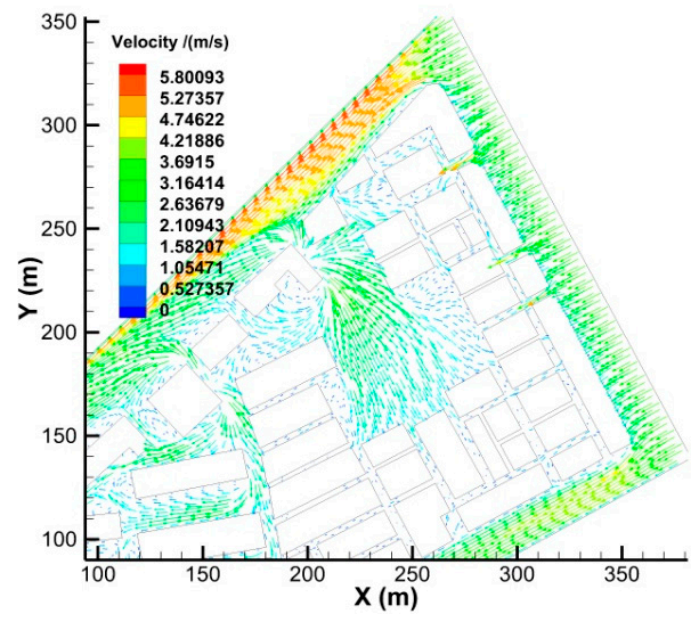

(a)

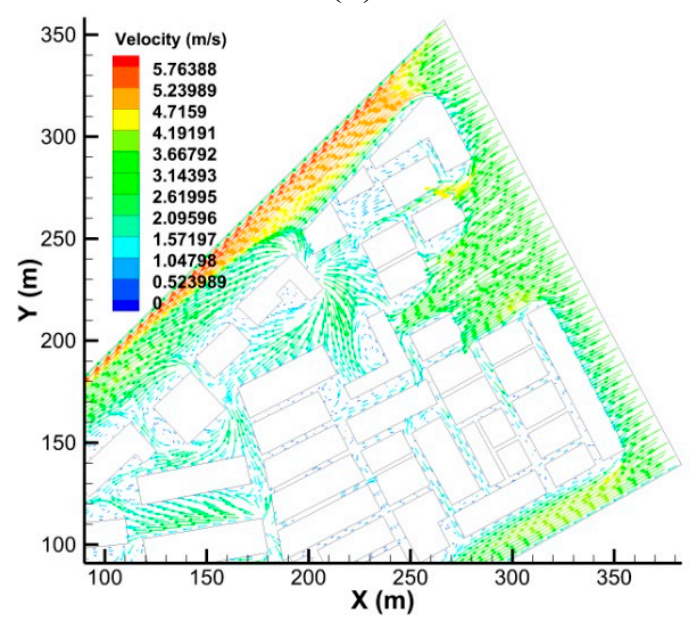

(c)

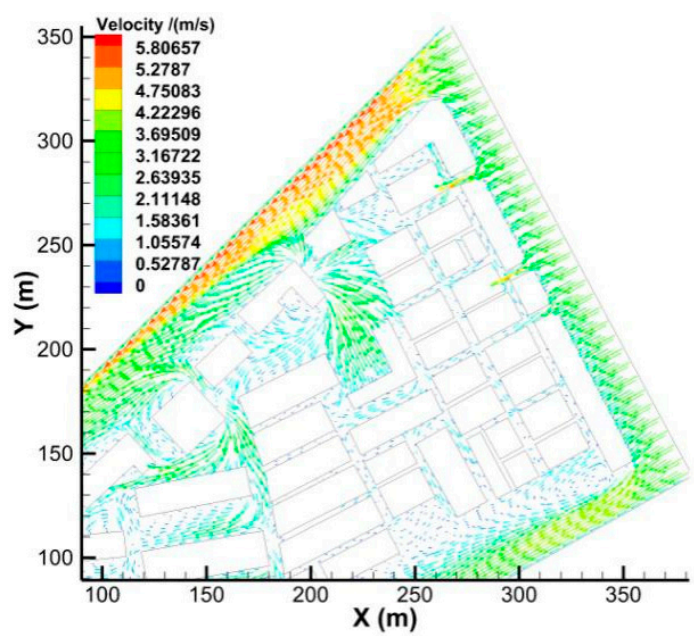

(b)

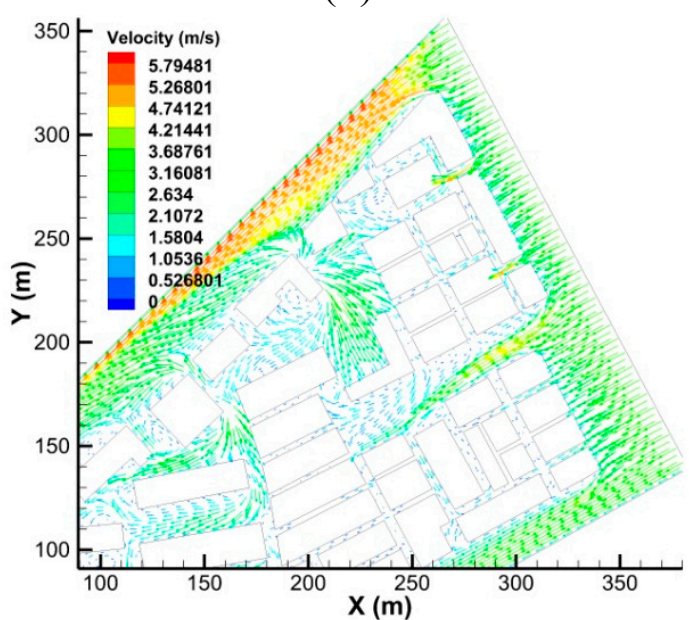

(d)

Figure 7. The comparison of velocity vectors of cross-section with height being $0.5 \mathrm{~m}$ of the urban renewal plans: (a) CD Plan; (b) ED Plan; (c) WSD Plan; (d) LSD Plan.

\subsection{Cross Shape Demolition Plan}

Based on the above analysis, a Cross Shape Demolition (CSD) Plan has been proposed and a numerical simulation on this plan has been performed. The results as shown in Figure 8 indicate the temperature and velocity distributions are obviously improved with the original highest temperature spots diminishing. Ambient crosswind flows both into the old city district and into the renewed area, improving the micro-climate of the whole study area. Compared with the four demolition plans shown above, CSD Plan creates two perpendicular wind passages with main wind passage aligning the prevailing wind. When faced with old districts of larger size, layout plans incorporating a network of wind passages will significantly improve the residents and pedestrians' wind and thermal environment. 


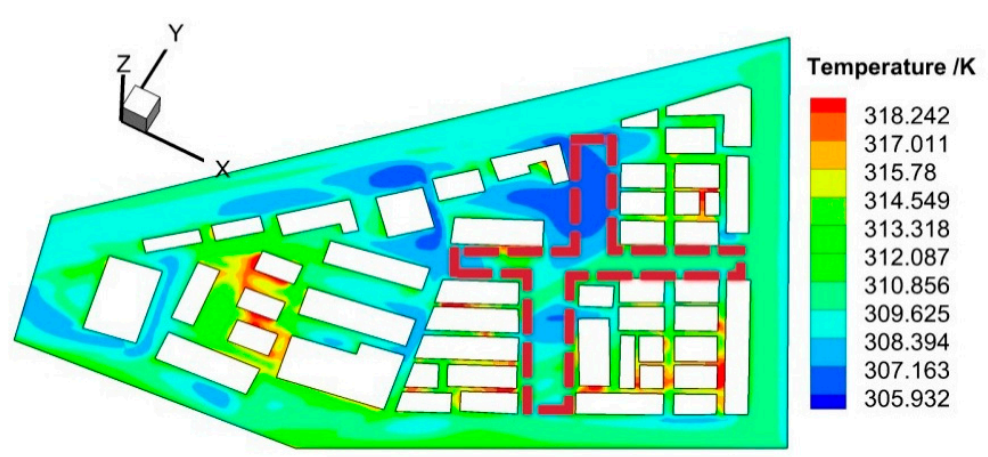

(a)

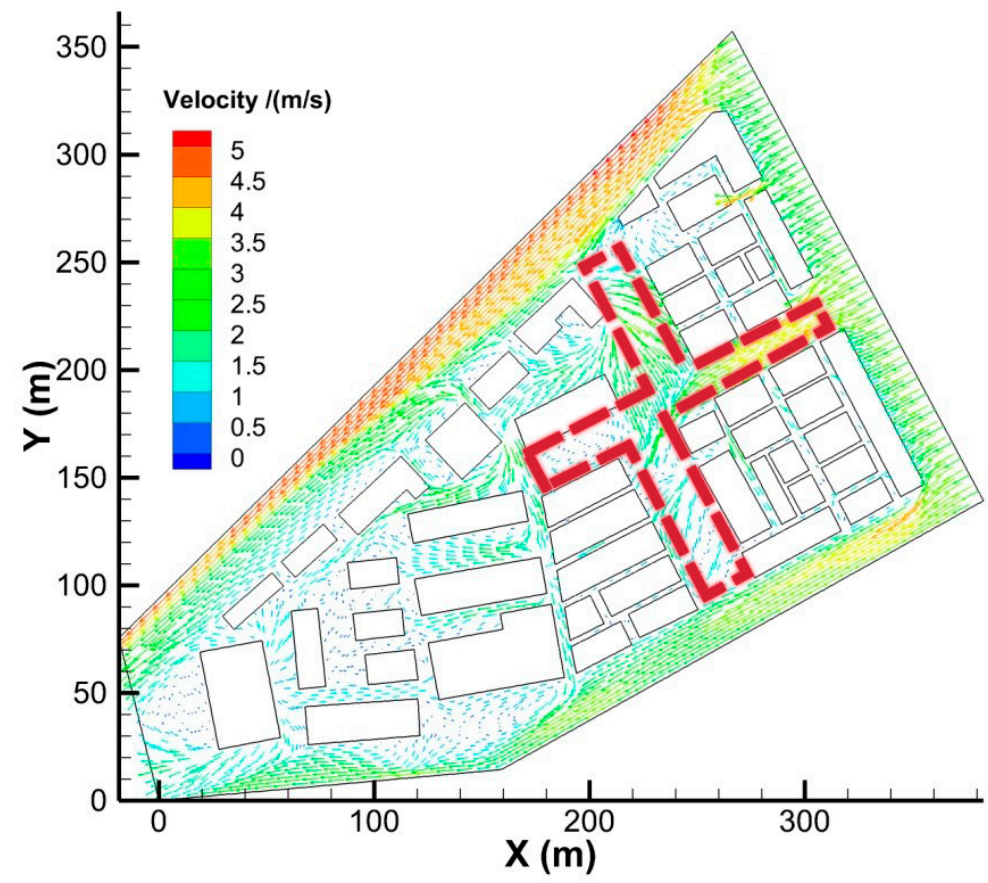

(b)

Figure 8. The results of cross-section with height being $0.5 \mathrm{~m}$ of Cross-shape Demolition Plan: (a) temperature distribution; (b) velocity vector.

\section{Discussion}

There are mainly two methods to optimize the conditions of air ventilation during urban renewal. One is to "create a wind", which can be achieved most effectively by planting certain amount of trees. However, this method is difficult to realize in old city districts with high building density. The other is to "induce a wind". That is, to create wind passages for the ambient crosswind to enter the study area. To be specific, wind passages are tunnels created strategically to bring fresh air flow into the urban areas with unfavorable thermal conditions. After being mixed with the fresh air flow, the air in the original area can be exported under the pressure of air flow, thus accelerating the air circulation (movement) in the micro-climate. Wind passages, or breezeways, play an important role in transmitting fresh air, mitigating urban heat island intensity, and dissipating air pollutants.

After comparing and analyzing the above proposals for urban renewal, it can be found that urban planners should take wind passages into account in the process of urban renewal. A few specific guidelines are summarized as follows. 
(1) Wind passages should be designed along prevailing wind directions

It is evident that when the buildings are demolished along the prevailing wind direction to form a wind passage (Figure 9), they no longer impede the outside ambient crosswind from penetrating inside the target area, and thus the permeability of urban air ventilation is increased dramatically. This can noticeably improve the outdoor wind and thermal environment in the old district. Consequently, the utilization of the site specific wind-rose information and incorporating wind passages along summer prevailing wind directions during urban renewal can effectively mitigate air ventilation and thermal problems.
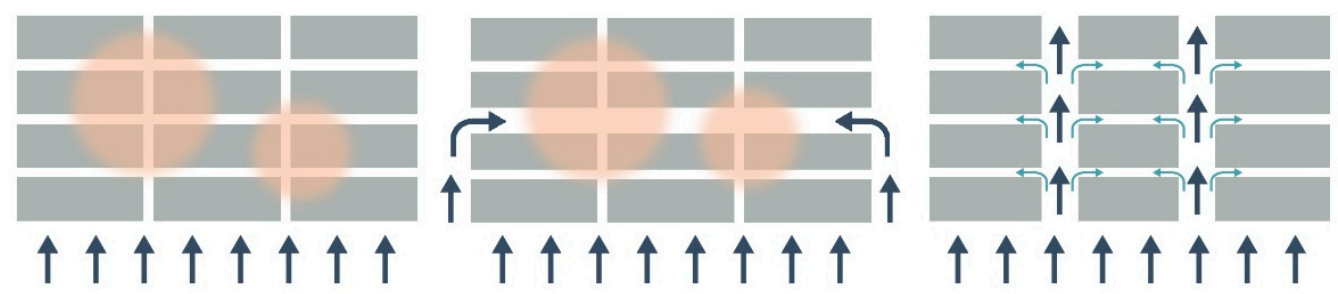

Figure 9. Creating wind passages along the prevailing wind direction.

(2) The entrances of wind passages are suggested as a funnel

According to the theory of fluid mechanics, a wedge shape wind passage opening to the outside upwind direction will to a large extent absorb the ambient crosswind (Figure 10). The absorbed fluid flow will penetrate the whole target district, and the wind and thermal environment will be greatly improved. In the five proposed demolition plans mentioned above, the third proposal in Figure $5 \mathrm{c}$, the WSD Plan, creates a funnel shaped open space at the entrance of the wind passage, which evidently alleviated the thermal problems.
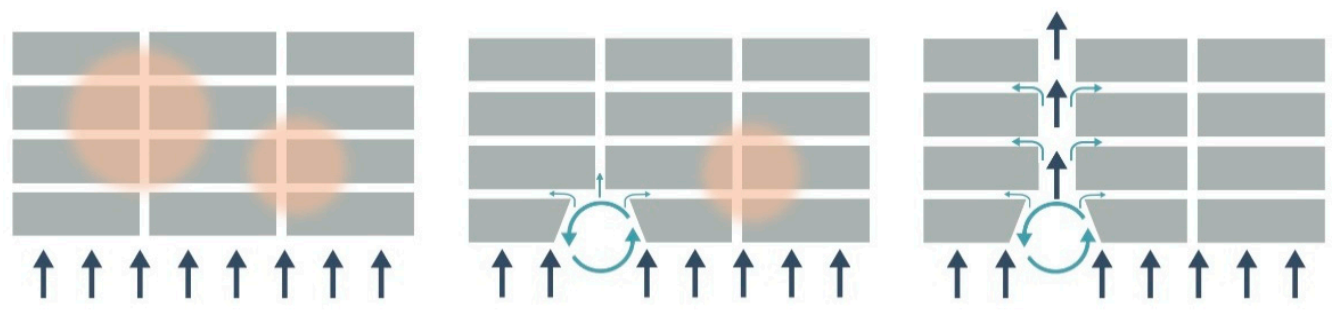

Figure 10. Broadening the entrance of wind passages.

(3) Wind passages should be connected as a network

All the four proposals in Figure 5 are beneficial to the air ventilation and thermal environment of the demolished area, but they are unable to improve the overall wind and thermal environment of the whole study area. One main reason is that the demolished buildings in these proposals are not enough and the related effect cannot cover the whole region. The cross shape demolition plan creates two perpendicular wind passages which cut through the whole district, allowing air to effectively flow into the whole area with dense buildings, which will effectively transfer the heat to the outside ambience and thus improve the local micro-climate. For this reason, the network of wind passages in old districts is crucial in large areas of old city districts during urban renewal (Figure 11). 

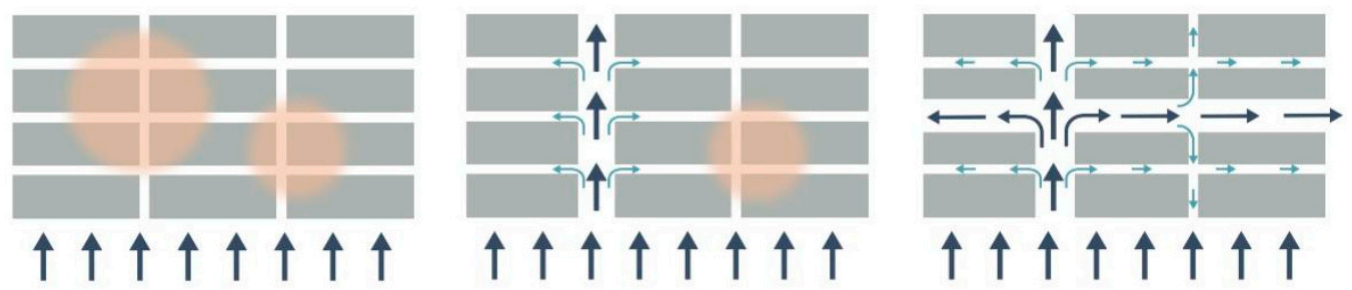

Figure 11. Creating a network of wind passages.

\section{Conclusions}

Urban renewal is a very complex topic covering not only social, economic, historical, and cultural issues, but also air quality, thermal comfort, and environmental ones as well. The present research has conducted a numerical analysis on an old city district undergoing urban renewal considering the effect of wind passages on the air quality, wind and thermal environment of the target area. Based on the results of the original urban renewal strategy, five new renewal strategies have been evaluated. From the results, some findings can be summarized as follows:

(1) The original renewal strategy, in which the demolished buildings and renewal buildings start from the leeward, is not an effective way to improve the overall wind and thermal environment of the target area as the lower old buildings of dense windward block the ambient crosswind from entering the system.

(2) The four renewal strategies, namely the Central Demolition (CD) Plan, Edge Demolition (ED) Plan, Wedge Shape Demolition (WSD) Plan, and "L" Shape Demolition (LSD) Plan, can partly improve the wind and thermal environment of the target area. However, the ED Plan and WSD Plan are superior as a wind passage is created within the old city district in each plan.

(3) A network of wind passages which connect with one another is more favorable to large areas of old city districts during urban renewal.

\section{Acknowledgments}

The authors would like to thank the supports from the National Natural Science Foundation of China (No. 51108199).

\section{Author Contributions}

Chong Peng conceived and designed the study; Chong Peng and Chu Li established the mathematical model; Zuyu Zou and Chong Peng performed the numerical simulation, improved the figures, and interpreted the data; Chong Peng, Suwan Shen and Dongqi Sun wrote the manuscript, Chong Peng and Suwan Shen revised the paper, Dongqi Sun provided good advices throughout the paper.

\section{Conflicts of Interest}

The authors declare no conflict of interest. 


\section{References}

1. Zhang, Y.; Fang, K. Is history repeating itself? From urban renewal in the United States to inner-city redevelopment in China. J. Plan. Educ. Res. 2004, 23, 286-298.

2. Chau, A.Y. An awful mark: Symbolic violence and urban renewal in reform-era China. Vis. Stud. 2008, 23, 195-210.

3. Wang, H.; Shen, Q.P.; Tang, B.S.; Skitmore, M. An integrated approach to supporting land-use decisions in site redevelopment for urban renewal in Hong Kong. Habitat Int. 2013, 38, 70-80.

4. Zheng, H.W.; Shen, G.Q.; Wang, H.; Hong, J. Simulating land use change in urban renewal areas: A case study in Hong Kong. Habitat Int. 2015, 46, 23-34.

5. Van der Horst, H.; Ouwehand, A. "Multicultural Planning" as a Contested Device in Urban Renewal and Housing: Reflections from The Netherlands. Urban Stud. 2012, 49, 861-875.

6. Raco, M. Business associations and the politics of urban renewal: The case of the Lower Don Valley, Sheffield. Urban Stud. 1997, 34, 383-402.

7. Olanrewaju, D.O. Urban infrastructure: A critique of urban renewal process in Ijora Badia, Lagos. Habitat Int. 2001, 25, 373-384.

8. Donaldson, R.; Plessis, D.D. The urban renewal programme as an area-based approach to renew townships: The experience from Khayelitsha's Central Business District, Cape Town. Habitat Int. 2013, 39, 295-301.

9. Arch, A.F. Sustainable Urban Renewal: The Tel Aviv Dilemma. Sustainability 2014, 6, 2527-2537.

10. Gold, J.R. A SPUR to action?: The Society for the Promotion of Urban Renewal, "anti-scatter" and the crisis of city reconstruction, 1957-1963. Plan. Perspect. 2012, 27, 199-223.

11. Gilbert, P. Becoming a homeowner on a social-housing estate. Small-scale residential promotions and changing lifestyles in a working-class neighbourhood undergoing urban renewal. Politix 2013, 26, 101, 79-104.

12. Schwenkel, C. Civilizing the City: Socialist Ruins and Urban Renewal in Central Vietnam. Positions Asia Crit. 2012, 20, 437-470.

13. Cheung, C.K.; Leung, K.K. Social Mitigation of the Impact of Urban Renewal on Residents' Morale. Soc. Indic. Res. 2012, 106, 523-543.

14. Smith, F.M. Discourses of citizenship in transition: Scale, politics and urban renewal. Urban Stud. 1999, 36, 167-187.

15. Pritchett, W.E. Race and community in postwar Brooklyn - The Brownsville neighborhood council and the politics of urban renewal. J. Urban Hist. 2001, 27, 445-470.

16. Dluhy, M.; Revell, K.; Wong, S. Creating a positive future for a minority community: Transportation and urban renewal politics in Miami. J. Urban Aff. 2002, 24, 75-95.

17. Ascunce, C.J. Incentivizing Local Reform and Urban Renewal during an Economic Crisis. Notre Dame Law Rev. 2013, 88, 1491-1520.

18. Hunter, R.F.; Tully, M.A.; Cleland, C.; Cupples, M.E.; Kee, F.; Prior, L.; Donnelly, M. The Impact of Urban Renewal on Engagement in Physical Activity in a Socio-Economically Disadvantaged Population: A Qualitative Evaluation. J. Epidemiol. Community Health 2010, doi:10.1136/ jech.2010.120477.38. 
19. Chan, E.H.W.; Lee, G.K.L. Contribution of Urban Design to Economic Sustainability of Urban Renewal Projects in Hong Kong. Sustain. Dev. 2008, 16, 353-364.

20. Weber, R.; O’Neill-Kohl, S. The Historical Roots of Tax Increment Financing, or How Real Estate Consultants Kept Urban Renewal Alive. Econ. Dev. Q. 2013, 27, 193-207.

21. Ferrante, A.; Mihalakakou, G. The influence of water, green and selected passive techniques on the rehabilitation of historical industrial buildings in urban areas. Sol. Energy 2001, 70, 245-253.

22. Sirayi, M. Cultural planning and urban renewal in South Africa. J. Arts Manag. Law Soc. 2008, 37, 333-344.

23. Melo, E.G.; Almeida, M.P.; Zilles, R.; Grimoni, J.A.B. Using a shading matrix to estimate the shading factor and the irradiation in a three-dimensional model of a receiving surface in an urban environment. Sol. Energy 2013, 92, 15-25.

24. Tooke, T.R.; Coops, N.C.; Christen, A.; Gurtuna, O.; Prevot, A. Integrated irradiance modelling in the urban environment based on remotely sensed data. Sol. Energy 2012, 86, 2923-2934.

25. Takebayashi, H.; Moriyama, M. Relationships between the properties of an urban street canyon and its radiant environment: Introduction of appropriate urban heat island mitigation technologies. Sol. Energy 2012, 86, 2255-2262.

26. Nikolopoulou, M.; Baker, N.; Steemers, K. Thermal comfort in outdoor urban spaces: Understanding the human parameter. Solar Energy 2001, 70, 227-235.

27. Santamouris, M.; Synnefa, A.; Karlessi, T. Using advanced cool materials in the urban built environment to mitigate heat islands and improve thermal comfort conditions. Solar Energy 2011, $85,3085-3102$.

28. Stavrakakis, G.M.; Koukou, M.K.; Vrachopoulos, M.G.; Markatos, N.C. Natural cross-ventilation in buildings: Building-scale experiments, numerical simulation and thermal comfort evaluation. Energy Build. 2008, 40, 1666-1681.

29. Mirzaei, P.A.; Haghighat, F. A procedure to quantify the impact of mitigation techniques on the urban ventilation. Energy Build. 2012, 47, 410-420.

30. Barkenbus, J. Indoor Thermal Comfort: The Behavioral Component. Sustainability 2013, 5, 1680-1699.

31. Lin, B.R.; Li, X.F.; Zhu, Y.X.; Qin, Y.G. Numerical simulation studies of the different vegetation patterns' effects on outdoor pedestrian thermal comfort. J. Wind Eng. Ind. Aerodyn. 2008, 96, 1707-1718.

32. Ali-Toudert, F.; Mayer, H. Numerical study on the effects of aspect ratio and orientation of an urban street canyon on outdoor thermal comfort in hot and dry climate. Energy Build. 2006, 41, 94-108.

33. Xu, Q.Z.; Luo, X.N. Dynamic thermal comfort numerical simulation model on 3D garment CAD. Appl. Math. Comput. 2006, 182, 106-118.

34. Ravikumar, P.; Prakash, D. Analysis of thermal comfort in an office room by varying the dimensions of the windows on adjacent walls using CFD: A case study based on numerical simulation. Build. Simul. 2009, 2, 187-196.

35. Filippin, C.; Ricard, F.; Larsen, S.F. Evaluation of heating energy consumption patterns in the residential building sector using stepwise selection and multivariate analysis. Energy Build. 2013, $66,571-581$. 
36. Filippin, C.; Larsen, S.F. Summer thermal behaviour of compact single family housing in a temperate climate in Argentina. Renew. Sustain. Energy Rev. 2012, 16, 3439-3455.

37. Filippin, C.; Larsen, S.F.; Mercado, V. Winter energy behaviour in multi-family block buildings in a temperate-cold climate in Argentina. Renew. Sustain. Energy Rev. 2011, 15, 203-219.

38. Wang, S.M.; Shen, Z.G. Effects of Roof Pitch on Air Flow and Heating Load of Sealed and Vented Attics for Gable-Roof Residential Buildings. Sustainability 2012, 4, 1999-2021.

39. Vollaro, A.D.; de Simone, G.; Romagnoli, R.; Vallati, A.; Botillo, S. Numerical Study of Urban Canyon Microclimate Related to Geometrical Parameters. Sustainability 2014, 6, 7894-7905.

40. Su, W.Z.; Zhang, Y.; Yang, Y.B.; Ye, G.B. Examining the Impact of Greenspace Patterns on Land Surface Temperature by Coupling LiDAR Data with a CFD Model. Sustainability 2014, 6, 6799-6814.

41. Peng, C.; Ming, T.; Gui, J.; Tao, Y.; Peng, Z. Numerical analysis on the thermal environment of an old city district during urban renewal. Energy Build. 2015, 89, 18-31.

42. Peng, C.; Ming, T.Z.; Cheng, J.Q.; Wu, Y.J.; Peng, Z.R. Modeling Thermal Comfort and Optimizing Local Renewal Strategies - A Case Study of Dazhimen Neighborhood in Wuhan City. Sustainability 2015, 7, 3109-3128.

43. Ahmad, K.; Khare, M.; Chaudhry, K.K. Wind tunnel simulation studies on dispersion at urban street canyons and intersections-A review. J. Wind Eng. Ind. Aerodyn. 2005, 93, 697-717.

44. Kastner-Klein, P.; Fedorovich, E.; Rotach, M.W. A wind tunnel study of organised and turbulent air motions in urban street canyons. J. Wind Eng. Ind. Aerodyn. 2001, 89, 849-861.

45. Pavageau, M.; Schatzmann, M. Wind tunnel measurements of concentration fluctuations in an urban street canyon. Atmos. Environ. 1999, 33, 3961-3971.

46. Cui, P.Y.; Li, Z.; Tao, W.Q. Investigation of Re-independence of turbulent flow and pollutant dispersion in urban street canyon using numerical wind tunnel (NWT) models. Int. J. Heat Mass Transf. 2014, 79, 176-188.

47. Chang, C.H.; Lin, J.S.; Cheng, C.M.; Hong, Y.S. Numerical Simulations and Wind Tunnel Studies of Pollutant Dispersion in the Urban Street Canyons with Different Height Arrangements. J. Mar. Sci. Technol. Taiwan 2013, 21, 119-126.

48. Chang, C.H.; Meroney, R.N. Concentration and flow distributions in urban street canyons: Wind tunnel and computational data. J. Wind Eng. Ind. Aerodyn. 2003, 91, 1141-1154.

49. Kovar-Panskus, A.; Louka, P.; Sini, J.F.; Savory, E.; Czech, M.; Abdelqari, A.; Mestayer, P.G.; Toy, N. Influence of geometry on the mean flow within urban street canyons-A comparison of wind tunnel experiments and numerical simulations. Water Air Soil Pollut. 2002, 2, 365-380.

50. Uehara, K.; Murakami, S.; Oikawa, S.; Wakamatsu, S. Wind tunnel experiments on how thermal stratification affects flow in and above urban street canyons. Atmos. Environ. 2000, 34, 1553-1562.

51. Minkowycz, W.; Sparrow, E. Advances in Numerical Heat Transfer; Taylor \& Francis: New York, NY, USA, 2000.

52. Ming, T.Z.; Wang, X.J.; de Richter, R.K.; Liu, W.; Wu, T.H.; Pan, Y. Numerical analysis on the influence of ambient crosswind on the performance of solar updraft power plant system. Renew. Sustain. Energy Rev. 2012, 16, 5567-5583.

53. Cermak, J.E. Applications of Fluid Mechanics to Wind Engineering-Freeman Scholar Lecture. ASME J. Fluids Eng. 1975, 97, 9-38. 
54. Tominaga, Y.; Mochida, A.; Yoshie, R.; Kataoka, H.; Nozu, T.; Yoshikawa, M.; Shirasawa, T. AIJ guidelines for practical applications of CFD to pedestrian wind environment around buildings. J. Wind Eng. Ind. Aerodyn. 2008, 96, 1749-1761.

55. Blocken, B.; Stathopoulos, T.; Carmeliet, J. CFD simulation of the atmospheric boundary layer: Wall function problems. Atmos. Environ. 2007, 41, 238-252.

56. Blocken, B.; Carmeliet, J.; Stathopoulos, T. CFD evaluation of wind speed conditions in passages between parallel buildings - Effect of wall-function roughness modifications for the atmospheric boundary layer flow. J. Wind Eng. Ind. Aerodyn. 2007, 95, 941-962.

57. Blocken, B.; Carmeliet, J. A review of wind-driven rain research in building science. J. Wind Eng. Ind. Aerodyn. 2004, 92, 1079-1130.

58. Oberkampf, W.L.; Trucano, T.G.; Hirsch, C. Verification, validation, and predictive capability in computational engineering and physics. Appl. Mech. Rev. 2004, 57, 345-384.

59. Toparlar, Y.; Blocken, B.; Vos, P.; van Heijst, G.J.F.; Janssen, W. D.; van Hooff, T.; Montazeri, H.; Timmermans, H.J.P. CFD simulation and validation of urban microclimate: A case study for Bergpolder Zuid, Rotterdam. Energy Build. 2015, 83, 79-90.

60. Montazeri, H.; Blocken, B.; Hensen, J.L.M. Evaporative cooling by water spray systems: CFD simulation, experimental validation and sensitivity analysis. Energy Build. 2015, 83, 129-141.

61. Montazeri, H.; Blocken, B.; Hensen, J.L.M. CFD analysis of the impact of physical parameters on evaporative cooling by a mist spray system. Appl. Therm. Eng. 2015, 75, 608-622.

62. Van Hooff, T.; Blocken, B. CFD evaluation of natural ventilation of indoor environments by the concentration decay method: $\mathrm{CO}_{2}$ gas dispersion from a semi-enclosed stadium. Energy Build. 2013, $61,1-17$.

63. Kubilay, A.; Derome, D.; Blocken, B.; Carmeliet, J. CFD simulation and validation of wind-driven rain on a building facade with an Eulerian multiphase model. Energy Build. 2013, 61, 69-81.

64. Ramponi, R.; Blocken, B. CFD simulation of cross-ventilation for a generic isolated building: Impact of computational parameters. Energy Build. 2012, 53, 34-48.

65. Montazeri, H.; Blocken, B.; Janssen, W.D.; van Hooff, T. CFD evaluation of new second-skin facade concept for wind comfort on building balconies: Case study for the Park Tower in Antwerp. Energy Build. 2013, 68, 179-192.

66. Montazeri, H.; Blocken, B. CFD simulation of wind-induced pressure coefficients on buildings with and without balconies: Validation and sensitivity analysis. Energy Build. 2013, 60, 137-149.

(C) 2015 by the authors; licensee MDPI, Basel, Switzerland. This article is an open access article distributed under the terms and conditions of the Creative Commons Attribution license (http://creativecommons.org/licenses/by/4.0/). 